\title{
Life Threatening Complications following Excision of Giant Neurofibroma
}

\author{
Jaeik Choi ${ }^{1}$, Yooseok Ha ${ }^{1}$, Hyun Woo Kyung ${ }^{1}$, Seung Han Song ${ }^{1}$, Nak Heon Kang ${ }^{1}$, Sang-Ha Oh, \\ ${ }^{1}$ Department of Plastic and Reconstructive Surgery, Chungnam National University, Daejeon; \\ ${ }^{2}$ Brain Research Institute, School of Medicine, Chungnam National University, Daejeon, Korea
}

\begin{abstract}
Neurofibroma is a common benign tumor, occurs anywhere in the body, grows continuously, and often becomes very large. 5-10\% of neurofibromas undergo malignant change. Surgical excision is the most effective method to control this tumor. However, it is hard to excise the tumor completely, and even partial excision is difficult due to the risk of hemorrhage. A 40-year-old female presented to our clinic with a huge neurofibroma on the back and posterior neck, and underwent surgical excision. She had uncontrolled bleeding during and after the operation, so she stayed in the intensive care unit for airway maintenance and hemodynamic stability (massive transfusion). After resuscitation, she had an extensive wound, repeated surgery nine times, and was hospitalized for fifty-four days. The lessons from this case when we excise huge neurofibromas are the following. 1) It is undesirable to excise tissues around the vital organs. 2) A careful preoperative design considering postoperative swelling and hemorrhage is necessary. A high tension in different directions after removal of the tumor may cause wound problems. 3) It is helpful to ligate feeding vessels via preoperative computed tomography angiography or angiogram.
\end{abstract}

Keywords: Neurofibroma, Hemorrhage, Excision

\section{Introduction}

Neurofibromatosis is an autosomal-dominant inheritable syndrome characterized by the presence of benign soft-tissue tumors within the peripheral nerves. It occurs anywhere in the body, continues to grow, and often becomes very large. Many different types of treatment have been tried for neurofibromatosis such as radiation, chemotherapy and gene therapy, but surgical excision is still the most effective method to control this tumor. ${ }^{1,2}$ It is difficult to manage, however, as it is highly vascular and extensively infiltrative.

We wish to share the experience of life threatening hemorrhage and wound problems after huge neurofibroma reduction and discuss cautions when performing neurofibroma reduction, with this case as an example.

\section{Case}

In 2015, an otherwise healthy 40-year-old Asian woman was hospitalized for a giant neurofibroma of the upper back and posterior neck (Figure 1). The neurofibroma extended into the midaxillary line and measured $60 \times 60 \mathrm{~cm}$. The lesion had been resected partially three times in 2003, 2007, and 2011. In 2011, 1,063 grams of tu-

\begin{abstract}
(a)
Check for

Case Report

Received: April 26, 2017

Revised: May 13, 2017

Accepted: May 15, 2017

\section{Corresponding author:}

Sang-Ha Oh, M.D., Ph.D.

Department of Plastic and Reconstructive Surgery, Chungnam National University, School of Medicine, 282 Munhwa-ro, Junggu, Daejeon 35015, Korea

Tel: +82-42-280-7380

Fax: +82-42-280-7384

E-mail:djplastic@cnu.ac.kr

No potential conflict of interest relevant to this article was reported.

This is an Open Access article distributed under the terms of the Creative Commons Attribution NonCommercial License (http://creativecommons.org/ licenses/by-nc/4.0/) which permits unrestricted noncommercial use, distribution, and reproduction in any medium, provided the original work is properly cited. (c) 2017 The Korean Wound Management Society
\end{abstract}


Choi J et al.

Complication after Neurofibroma Excision
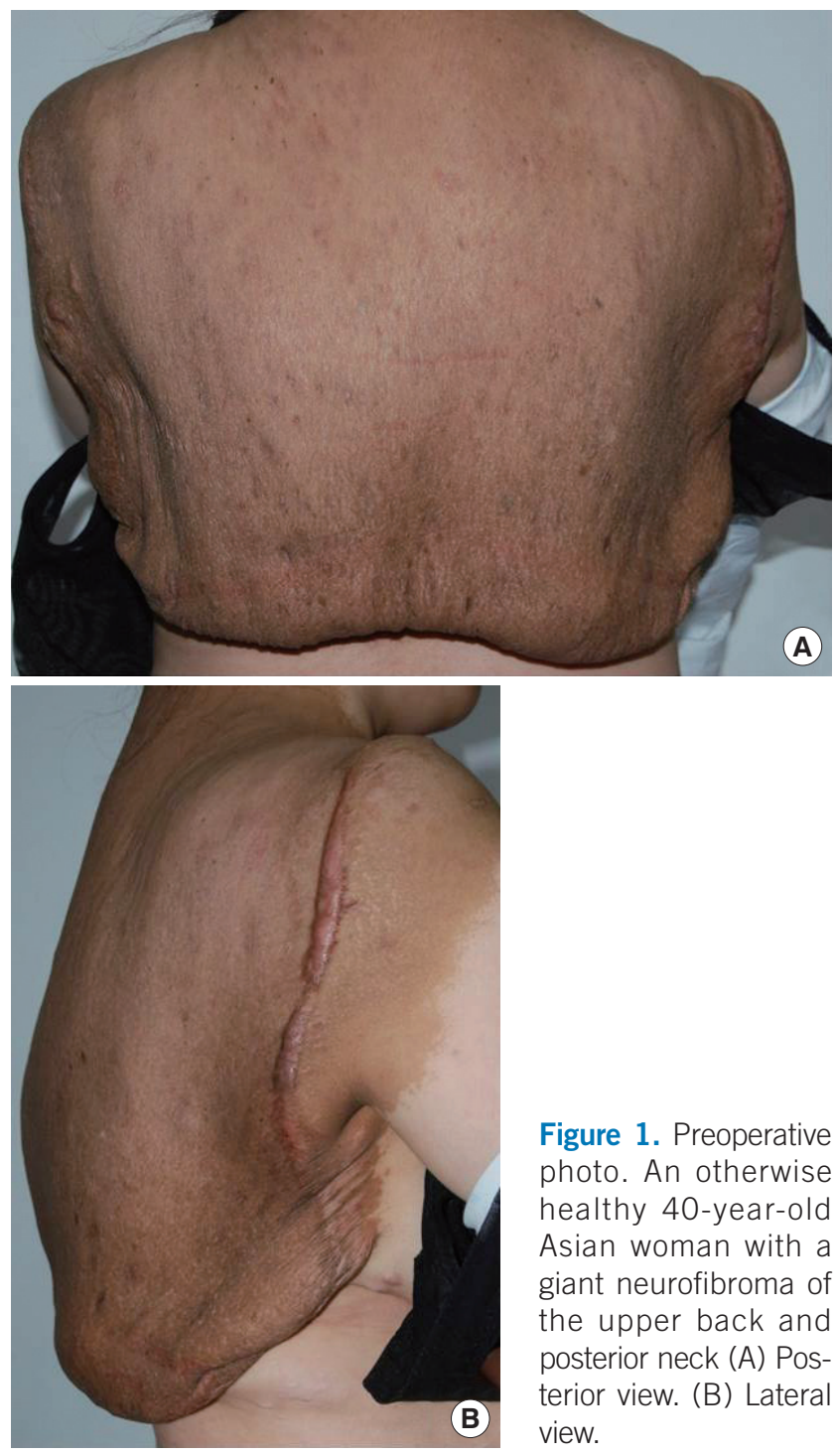

Figure 1. Preoperative photo. An otherwise healthy 40-year-old Asian woman with a giant neurofibroma of the upper back and posterior neck (A) Posterior view. (B) Lateral view.

mor was partially resected, the wound healed uneventfully and the patient was discharged after 14 days. Over the next four years, the tumor gradually enlarged and impaired the patient's daily life. No contrast-enhanced Computed Tomography (CT), Magnetic Resonance Imaging (MRI) or angiography were performed before the operation. The reason why no imaging study was performed is that the extent or depth of invasion could be estimated from the three previous operations.

The operation was performed under general anesthesia in the prone position. A $50 \times 30 \mathrm{~cm}$ cross (midline with transverse) incision and a $40 \times 25 \mathrm{~cm} \mathrm{U}$-shaped incision were made from the upper back and posterior neck (Figure 2), and 900 grams of tumor was resected. Profuse bleeding was noticeable during the excision. During the operation, the patient

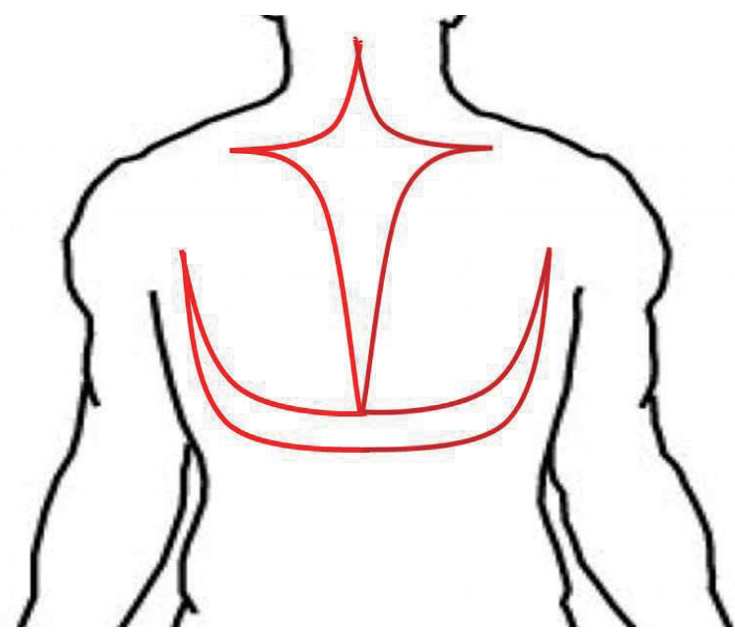

Figure 2. Schematic view of preoperative design. A cross (midline with transverse) incision and a U-shaped incision were made from the upper back and posterior neck.

lost over $1,500 \mathrm{~mL}$ of blood, so $1,030 \mathrm{~mL}$ of blood plasma and red cell suspension was transfused. After a short period of compression, the wound itself was closed in layers with drainage.

Following the operation, a hematoma gradually developed in the neck and back region and the patient felt neck tightness and mild discomfort when breathing. Bedside hematoma evacuations were performed three times, relieving the symptoms for a couple of hours. Despite the evacuations, however, the hematoma continued to grow in the neck region and threatened to endanger the patient's breathing and vital circulation.

On postoperative day (POD) 2, the patient was moved to the Intensive Care Unit for mechanical ventilation and hemodynamic stabilization. Her hemoglobin level dropped to $5.9 \mathrm{~g} /$ $\mathrm{dL}$ (from $12.3 \mathrm{~g} / \mathrm{dL}$ ) despite massive transfusions during the first four postoperative days (Red Blood Cells 40 packs, Fresh Frozen Plasma 32 packs, Platelet 24 packs). The patient was tachycardic and hypotensive, with the mean arterial pressure dropped to $55-65 \mathrm{mmHg}$ with the use of vasopressors (norepinephrine $(0.1 \mathrm{mcg} / \mathrm{kg} / \mathrm{min})$. Contrast enhanced CT angiogram to find the feeding vessels to the tumor followed by vascular intervention was considered. However, CT angiogram did not find the feeding vessels, but multifocal extravasation with extensive hematoma, so embolization could not be performed.

On POD 4, her hemoglobin level began to rise with the transfusion and we assumed that profuse bleeding had stopped. With the hemodynamic stabilization and release of 


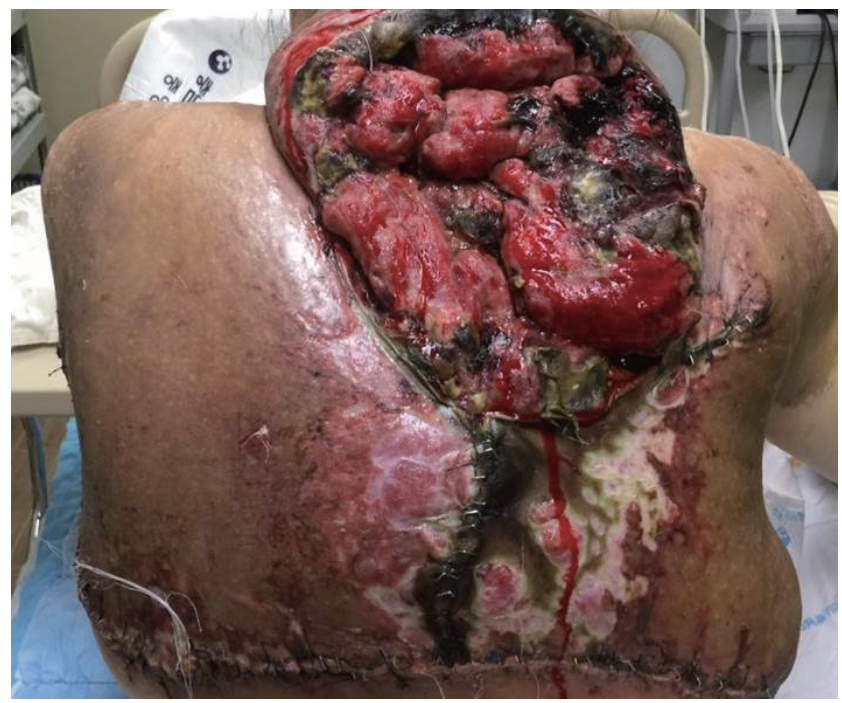

Figure 3. Postoperative photo. Wide range of skin necrosis and hematoma (POD 10).

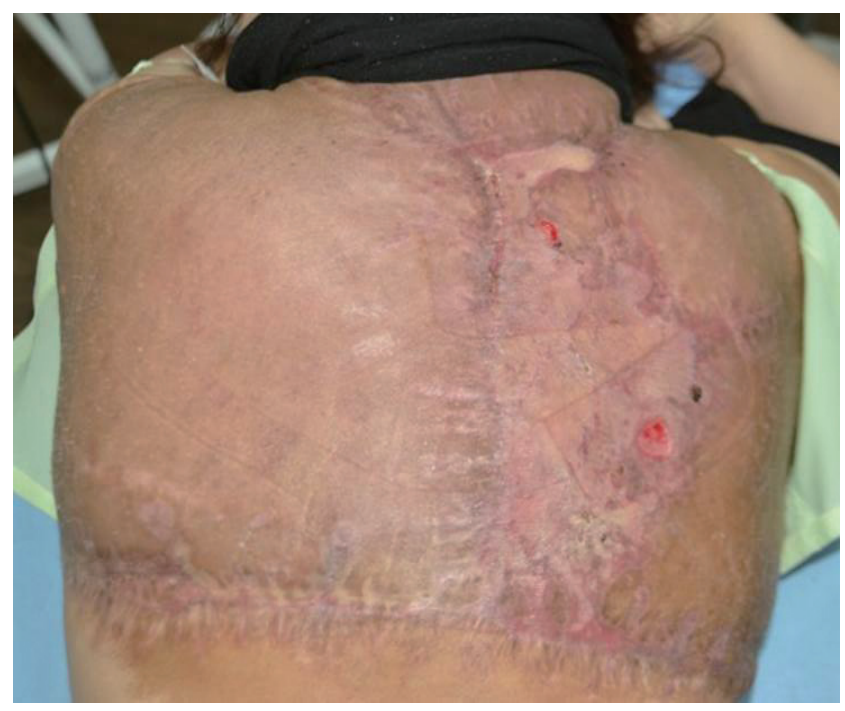

Figure 5. Postoperative photo. Later photo at the outpatient clinic after discharge (POD 72).
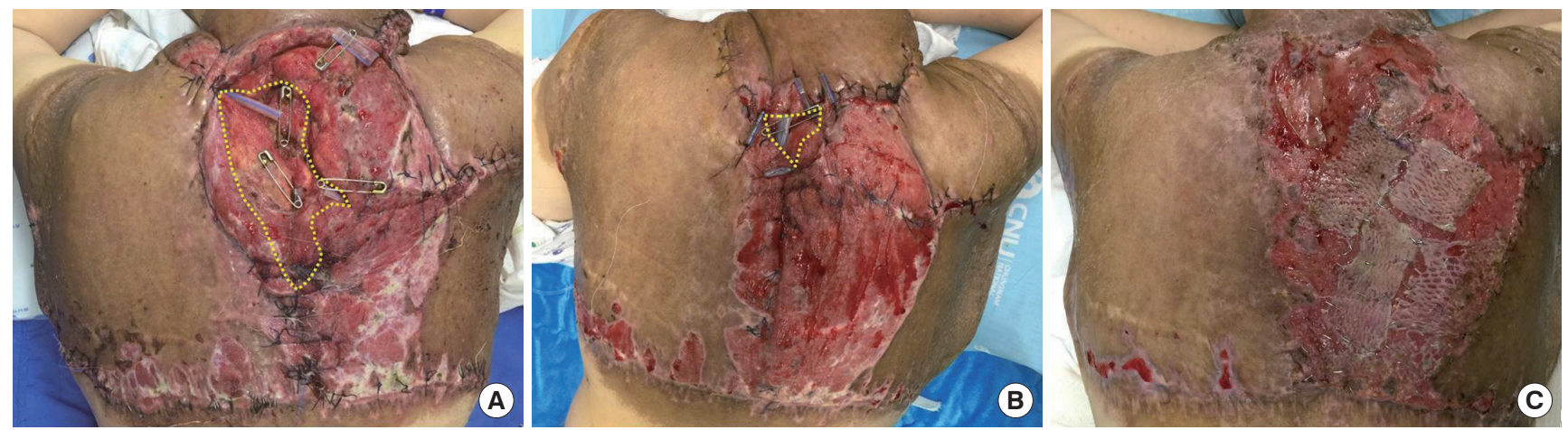

Figure 4. Postoperative photo. Wound edges were approximated by local advancement flaps to cover the defect, and remaining wounds that were difficult to suture were covered by split-thickness skin grafts. (A) Decreasing the size of the wound with local advancement flaps (POD 15). (B) Decreasing the size of the wound with local advancement flaps (POD 23). (C) Split thickness skin graft for remaining wounds (POD 34).

neck tightness, the endotracheal tube was removed. On POD 5 , the patient was shifted to a general ward. There were a wide range of wound dehiscence and necrosis along the margin (Figure 3). Wet-to-dry dressings were applied three times throughout the day until the wound was cleared of all non-viable tissue. Wound edges were approximated by local advancement flaps to cover the defect, and remaining wounds that were difficult to suture were covered by splitthickness skin grafts (Figure 4).

On POD 49, the surgical wound eventually healed and the patient was discharged, and examined regularly in an outpatient clinic. There was considerable improvement in her appearance and mobility (Figure 5).

\section{Discussion}

Neurofibromatosis excision is difficult because of the intractable hemorrhage, so it usually excised in stages with large tumors. ${ }^{1-3}$ Many different surgical techniques have been developed to reduce perioperative hemorrhage such as electrosurgery, ${ }^{4}$ LigaSure system, ${ }^{5}$ and application of adhesive or thrombotic materials. ${ }^{6}$ However, they are ineffective in friable tissues, as it is difficult to find the edge of vessels. ${ }^{7}$ Resection using Tsukisui device does not require extended surgical time and special skills, but the size of the tumor that can be resected tends to be limited. ${ }^{8}$ Undersewing the feeding vessels is an effective way to control the bleeding, as it ligates the vascular pedicle, ${ }^{11}$ but it is limited, as bleeding is profuse and 
the edge of vessels can be hard to find. Non-encapsulated tumors mingling with surrounding tissues and thin walled abnormal feeding vessels make it more difficult to control the hemorrhage. ${ }^{10,11}$

Preoperative intravascular embolization has many advantages, and it is a useful treatment for life-threatening hemorrhage. However, embolization poses a risk of skin necrosis, and the precise target vessel cannot always be found. ${ }^{12,13}$ Skin necrosis can be reduced with a distal embolization technique. $^{14}$

Although life-threatening intraoperative and postoperative hemorrhage in neurofibroma is uncommon, it has been reported in the literature. Most refer to hemodynamic instability due to intractable bleeding causing life-threatening hematoma in neurofibroma, ${ }^{15}$ although airway compression caused by hematoma is another important mechanism.

In our case, the patient underwent three previous operations for the neurofibroma. In the third operation (2011), 1,063 grams of tumor was partially resected; the wound healed uneventfully. At that time, operation was performed only on the back region, not on the neck region. This time (2015), in comparison, a lesser amount of tumor (900 grams) was resected, but the patient suffered from a life threatening hematoma. We assume the main reason for this was the cross incision we made over the posterior neck region. Too many incisions and too much resection caused massive hematoma in the posterior neck, and eventually neck tightness and airway compression.

Taking this into account, management of neurofibroma must be individualized for each patient. After detailed consultation with the patient, cautious preoperative design considering the amount and extent of the tumor resected should be performed. Special attention should be paid to neurofibromas localized in the neck region, especially near the airway, and excision should not be excessive.

It is important to assess the risk of profuse bleeding preoperatively and autologous blood transfusion should be considered to reduce the amount of allogenic blood transfusion.

\section{Conclusion}

In conclusion, when excising a giant neurofibroma, we suggest: 1) It is undesirable to excise tissues around the vital organs, 2) A careful preoperative design considering postoperative swelling and hemorrhage is necessary. A high tension after removal the tumor in different directions may cause wound problems, and 3) It is helpful to ligate feeding vessels via preoperative computed tomography angiography or angiogram preoperatively.

\section{Acknowledgments}

This research was supported by Basic Science Research Program through the National Research Foundation of Korea (NRF) funded by the Ministry of Science, ICT \& Future Planning (NRF-2013R1A1A1057928).

This work was supported by research funds of Chungnam National University.

\section{References}

1. Janes LE, Sabino J, Matthews JA, et al. Surgical management of craniofacial neurofibromatosis type 1 associated tumors. J Craniofac Surg 2013;24:1273-7.

2. Kim SH, Roh SG, Lee NH, et al. Radiofrequency ablation and excision of multiple cutaneous lesions in neurofibromatosis type 1. Arch Plast Surg 2013;40:57-61.

3. Ghareeb FM, Makeen K, Fawzy AT, et al. Facial neurofibromatosis: Cosmetic considerations. Egyptian J Plast Reconstr Surg 2001;25:139-46.

4. Nahabedian MY, Rozen SM, Namnoum JD, et al. Giant plexiform neurofibroma of the back. Ann Plast Surg 2000;45: 442-5.

5. Konno E, Kishi K. Use of the LigaSure vessel sealing system in neurofibroma excision to control postoperative bleeding. J Plast Reconstr Aesthet Surg 2012;65:814-7.

6. Stojicic M, Tacevic Z, Novkovic M, et al. Application of adhesive tissues to control bleeding in surgical treatment of neurofibromatosis. J Plast Reconstr Aesthet Surg 2009;62: e492-4.

7. Francis DM, Mackie W. Life-threatening haemorrhage in patients with neurofibromatosis. Aust N Z J Surg 1987;57:67982.

8. Maeda T, Kimura C, Takahashi K, et al. Utility of the method using the tsukisui device to control intraoperative bleeding applied to neurofibroma resection. Plast Reconstr Surg Glob Open 2014;1:e85.

9. Lin YC, Chen HC. Rare complication of massive hemorrhage in neurofibromatosis with arteriovenous malformation. Ann Plast Surg 2000;44:221-4.

10. Rha EY, Lim SY, Shim HS. Bimodal treatment of a huge hypervascular neurofibroma on the groin. Arc Plast Surg 2015; 42:486-9.

11. Poston GJ, Grace PA, Venn G, et al. Recurrent near-fatal haemorrhage in von Recklinghausen's disease. $\mathrm{Br} J$ Clin 
Pract 1990;44:755-6.

12. Jones RG, Kiatisevi P, Morris DC, et al. Intravascular embolisation and surgical resection of a giant neurofibroma with intratumoural haemorrhage. Br J Radiol 2010;83:e225-9.

13. Pelage JP, Le Dref O, Mateo J, et al. Life-threatening primary postpartum hemorrhage: treatment with emergency selective arterial embolization. Radiology 1998;208:359-62.
14. Vélez R, Barrera-Ochoa S, Barastegui D, et al. Multidisciplinary management of a giant plexiform neurofibroma by double sequential preoperative embolization and surgical resection. Case Rep Neurol Med 2013;2013:987623.

15. Rao V, Affifi RA, Ghazarian D. Massive subcutaneous hemorrhage in a chest-wall neurofibroma. Can J Surg 2000;43: 459-60. 